\title{
Téoros
}

Revue de recherche en tourisme

\section{Le tourisme en voie de mondialisation}

\section{Marc Laplante}

Volume 6, numéro 3, décembre 1987

Le tourisme, phénomène mondial

URI : https://id.erudit.org/iderudit/1080597ar

DOI : https://doi.org/10.7202/1080597ar

Aller au sommaire du numéro

Éditeur(s)

Université du Québec à Montréal

ISSN

0712-8657 (imprimé)

1923-2705 (numérique)

Découvrir la revue

Citer ce document

Laplante, M. (1987). Le tourisme en voie de mondialisation. Téoros, 6(3), 1-1. https://doi.org/10.7202/1080597ar d'utilisation que vous pouvez consulter en ligne.

https://apropos.erudit.org/fr/usagers/politique-dutilisation/ 
Pour traiter du tourisme comme phénomène mondial, fautil se percher sur un satellite géo-stationnaire? Peut-être pas, mais il faut du recul. Contemplez un globe terrestre avec les statistiques de l'Organisation mondiale du tourisme en mains: phs d'une centaine de pays, sur les 203 inscrits à I'ONU, sont "hors-circuits" touristiques; les Caraibes et la Méditerranée accaparent /'essentiel du tourisme international; les pays en développement qui recoivent pour la peine des visiteurs sont très peu nombreux, etc. L'analyse des flux touristiques entre les grandes régions du monde, présentée par Jean Stafford et Paul Bodson, nous dit comment l'expansion internationale est récente et leurs prévisions jusqu'à l'an 2000 tracent les grandes limites du développement probable.

Cette vue globale est, en fait, un préalable ả la compréhension de plusieurs aspects du tourisme international que Téoros vous propose aujourd'hui d'examiner. Robert Lanquar, par exemple, nous entraine à imaginer le celebre bassin méditérranéen d'jci 40 ans. il faudra beaucoup de courage aux décideurs pour éviter qu'li ne croule sous le nombre de touristes. Marc Laplante, pour sa part, interroge les attitudes nouvelles des pays en développement quiont misé sur le tourisme depuis 15 ou 20 ans comme contribution à leur démarrage économique.

Limmense mouvement des peuples du nord vers la ceinture du Soleil, qui explique à lui seul presque tout le tourisme international, n'est pas uniquement menacé par la couche d'ozone de plus en plus trouée; sur cette ceinture, le tourisme se développe dans des micro-sociétés qui ne peuvent que tres rarement personnaliser leurs produits. Un risque de standardisation est certain et les promoteurs de ce genre de voyages doivent toujours diversifier leurs destinations. Parviendront-ils a coloniser le Pacifique? Pascal Tremblay, installé en Australie, examine les opérations de promotion que doivent faire plusieurs pays de ce bout du monde pour attirer des visiteurs. On apprendra surtout que les nouveaux riches de l'extrême orient sont en train de se doter de terrains de jeux ensoleilles dans le Pacifique comme nous /'avons fait, nous de /'Amérique du Nord, dans les Antilles. Est-ce finalement cela le tourisme intemational?

Regardons alors les choses autrement: le tourisme international serait important à cause de sa place dans l'économie de plus en plus mondialisée. Que l'industrie touristique soit en voie de mondialisation. Thierry Quintrie La Mothe, un collaborateur de la revue francaise Espaces, le montre tres bien et en tire des consequences parfois inquetantes. Mais il faudrait, une fois de phs, prendre du recul pour approfondir cet aspect; par exemple, pour les quelques trente pays du monde qui recoivent chaque année des milhons de touristes, les recettes touristiques, en pourcentage du produit national brut, ne représentent que de $1 \%$ a $2 \%$. à quelques exceptions près. Ces économies, extrêmement importantes pour l'économie mondiale, ne risquent pas d'être bouleversées par le tourisme, peu importe ce qui peut hi arriver dans lavenir.
Faut-1/ continuer, pour autant, à considérer les aspects inter nationaux du tourisme, comme des épiphénomènes? Comme des questions réservées aux experts? Au Québec. nous serions justifies de raisonner ainsi: /'essentiel de notre tourisme est national et, en matiere de rapports internationaux liés au tourisme, nous $n$ 'avons qu'une seule expérience: la visite des américains. Le passé a ce propos, n'est pas garant de l'avenir, nous disent Marie-Hélène Courtade et Guy Leroux. Plus récemment, le Québec a sentila nécessité d'ïntéresser d'autres marchés internationaux mais Claude Tanguay raconte dans une entrevue le nouveau contexte de haute compétition mondiale dans lequel le ministère du Tourisme doit opérer pour atteindre cet objectif.

L'état de "guerre" commerciale actuelle sur la scène du monde pour maintenir des marchés et tenter de "séduire" de nouvelles clienteles est peut-être un signe des temps. La France "refait" entièrement Le Louvre et Versailles et le tout sera complété quand Eurodysneyland ouvira ses portes à 40 kilomètres de Paris/ La mondialisation de I'industrie touristique est peut-etre finalement plus conséquente aux niveaux politique et culturel qu'á celui de l'économie. dans un futur contexte qui ne favorisera plus autant les vacances longues et éloignées, il faudra bien trouver l'aven. ture, l'exotisme, la découverte, etc., plus vite et plus prés de chez soi. Les "vieux" pays récepteurs de touristes sont de plus en plus sollicités pour offrir davantage à leurs visiteurs. Quoi? Essentiellement, des aspects moins visibles de leurs réalités, de leur histoire, de leurs modes et styles de vie. Dans le futur Versailles, on visitera toujours la galerie des Glaces, mais on pourra aussi diner comme au temps du Roi Soleill

La mondialisation du tourisme ne serait donc pas, comme on le pense à première vue, une expansion dans l'espace géographique, mais une pénétration dans les espaces sociaux et culturels. Jeffrey O'Malley, en faisant le bilan des études sur les relations entre l'Art et le tourisme, arrive à des interrogations majeures: récupération de la culture pour / intégrer aux produits touristiques? Résistance culturelle? Yves Léger rencontre les mêmes questions en discutant d'un tourisme possible en terre amérindienne. Cen'est pas par hasard que les études se multiplient, au Québec comme allleurs, surles manifestắtions culturelles et le tourisme; linnocente, la sympathique et l'authentique "fete au village" d'autrefois, temps fort annuel des communautés humaines, est prise d'assaut simu/tanément dans tous les pays d'accuell pour faire le bonheur des étrangers de passage! Les standardisations qui risquent d'en résulter seront autrement p/us perturbatrices que la banalisation des aérogares, des chambres d'hotels ou des tours de ville en carl $f$

Marc Laplante 